\title{
10 health stories that mattered: Apr. 12-17
}

- There is increasing demand for priority health procedures (radiation therapy, joint replacement, hip-fracture repair and cataract surgery) but wait times have remained stable, according to a report by the Canadian Institute for Health Information. Between 2010 and $2014,80 \%$ of patients received care within established benchmarks.

- Health Canada launched a 60-day public consultation on proposed changes to labels for weed-control products containing glyphosate (such as Roundup) to better protect human health and the environment. The new labels would make recommendations about avoiding toxic doses, prolonged or unintended exposure, drift to populated areas and run-off to aquatic habitats.

- The Chief Public Health Officer of Canada travelled to West Africa to witness ongoing efforts to fight the Ebola outbreak. Dr. Gregory Taylor will visit 70 Canadian health care workers in Guinea and Sierra Leone.

- A dozen cases of E. coli may be linked to leafy greens, though no product has yet been identified, stated the Public
Health Agency of Canada. The agency is investigating cases with federal and provincial health partners in Alberta (9), Saskatchewan (1), Ontario (1) and Newfoundland and Labrador (1).

- The Treasury Board reversed a decision that would have forced federal health workers to strike if contract negotiations between unions and the government break down. The 3400 medical professionals in the public service across Canada will instead have access to arbitration.

- A group of Canadian Forces veterans are riding across Canada on horseback to raise awareness about mental health problems in the military such as post-traumatic stress disorder and suicide. The ride, organized by the Communities for Veterans Foundation, began in British Columbia and is expected to take about 200 days.

- An \$842-million project in British Columbia to transfer about 1.1 million patient records to a digital database is behind schedule, and three health authorities have abandoned their contracts with IBM to look for new vendors. According to Health Min- ister Terry Lake, however, the "One Person, One Record" project will still be completed on budget.

- An Ontario judge ordered a 10-yearold girl to receive the MMR (measles, mumps, rubella) vaccine and told the girl's mother not to speak negatively to her about vaccination. The girl's father insisted she get the vaccine before a trip to Germany.

- More than 250 Ontario nurses will be laid off as hospitals attempt to reduce costs. Political opponents of the ruling Ontario Liberal Party have blamed the layoffs on budget freezes for hospitals.

- An NDP government in Alberta would restore unused space in hospitals, cancel a plan to reorganize Alberta Health Services and reverse $\$ 160$ million of heath care cuts proposed by the existing Conservative government, announced party leader Rachel Notley. Health care was a hot topic in Alberta leading up to the May 5 provincial election. - Roger Collier, CMAJ

CMAJ 2015. DOI:10.1503/cmaj.109-5045 